\title{
Absence of association between Plasmodium falciparum small sub-unit ribosomal RNA gene mutations and in vitro decreased susceptibility to doxycycline
}

\author{
Tiphaine Gaillard ${ }^{1,2,3}$, Nathalie Wurtz ${ }^{1,2,4}$, Sandrine Houzé ${ }^{5,6,7}$, Kanlaya Sriprawat ${ }^{8}$, Chirapat Wangsing ${ }^{8}$, \\ Véronique Hubert ${ }^{5,7}$, Jacques Lebras ${ }^{5,6,7}$, François Nosten ${ }^{8,9}$, Sébastien Briolant ${ }^{1,2,10,11}$, Bruno Pradines ${ }^{1,2,4,12^{*}}$ \\ and The French National Reference Centre for Imported Malaria Study Group
}

\begin{abstract}
Background: Doxycycline is an antibiotic used in combination with quinine or artesunate for malaria treatment or alone for malaria chemoprophylaxis. Recently, one prophylactic failure has been reported, and several studies have highlighted in vitro doxycycline decreased susceptibility in Plasmodium falciparum isolates from different areas. The genetic markers that contribute to detecting and monitoring the susceptibility of P. falciparum to doxycycline, the pfmdt and pftetQ genes, have recently been identified. However, these markers are not sufficient to explain in vitro decreased susceptibility of P. falciparum to doxycycline. In this paper, the association between polymorphism of the small sub-unit ribosomal RNA apicoplastic gene pfssrRNA (PFC10_API0057) and in vitro susceptibilities of P. falciparum isolates to doxycycline were investigated.
\end{abstract}

Methods: Doxycycline $I_{50}$ determinations using the hypoxanthine uptake inhibition assay were performed on 178 African and Thai P. falciparum isolates. The polymorphism of pfssrRNA was investigated in these samples by standard PCR followed by sequencing.

Results: No point mutations were found in pfssrRNA in the Thai or African isolates, regardless of the determined $\mathrm{IC}_{50}$ values.

Conclusions: The pfssrRNA gene is not associated with in vitro decreased susceptibility of P. falciparum to doxycycline. Identifying new in vitro molecular markers associated with reduced susceptibility is needed, to survey the emergence of doxycycline resistance.

Keywords: Malaria, Plasmodium falciparum, In vitro, Anti-malarial, Molecular marker, Doxycycline, Small ribosomal sub-unit RNA gene, pfssrRNA, 16S rRNA

\section{Background}

Doxycycline is an effective anti-malarial prophylactic drug when administered as a monotherapy 1 day before, daily during, and for 4 weeks after return from travel to an area where malaria is endemic. Doxycycline

\footnotetext{
*Correspondence: bruno.pradines@free.fr

${ }^{1}$ Unité de Parasitologie, Département d'Infectiologie de Terrain, Institut de Recherche Biomédicale des Armées, Marseille, France

Full list of author information is available at the end of the article
}

is currently a recommended chemoprophylactic regimen for travellers visiting areas where malaria is endemic and has a high prevalence of chloroquine or multidrug resistance [1-3]. The World Health Organization also recommends doxycycline in combination with quinine or artesunate as the second-line treatment for uncomplicated Plasmodium falciparum malaria [2].

Most prophylactic failures of doxycycline against $P$. falciparum were associated with the use of inadequate, low doses or poor compliance [4-6]. However, resistance 
could also explain prophylactic failures with doxycycline. Cyclines resistance has been documented in Plasmodium berghei as a consequence of minocycline drug pressure in a $P$. berghei murine malaria model [7]. Recently, one prophylactic failure has been reported [8].

A Bayesian mixture modelling approach identified three different phenotypes (low, medium, and high doxycycline $\mathrm{IC}_{50}$ phenotypic groups) among $P$. falciparum African clinical isolates [9, 10]. Using 90 isolates from 14 African countries, it was demonstrated that increases in copy numbers of $P$. falciparum metabolite drug transporter gene (Pfmdt, PFE0825w) and P. falciparum GTPase TetQ gene (PfTetQ, PFL1710c) are associated with reduced susceptibility to doxycycline [11], and this association was later confirmed in African P. falciparum isolates [9]. In addition, isolates with PfTetQ KYNNNN motif repeats $<3$ are associated with in vitro reduced susceptibility to doxycycline and with a significantly higher probability of having an $\mathrm{IC}_{50}$ above the doxycycline resistance threshold of $35 \mu \mathrm{M}$ (odds ratio of 15) [11, 12]. The isolate obtained from the patient with prophylactic resistance to doxycycline harboured two copies of $p f m d t$ and two PfTetQ KYNNNN motif repeats [8], consistent with previous in vitro data [12].

However, some recent publications have demonstrated that these molecular markers were certainly not only encountered in cases of reduced susceptibility to doxycycline $[13,14]$ and were not associated with resistance in Thai isolates [14]. Therefore, it is necessary to investigate other hypotheses. Based on bacterial world, proteins homologue to those implicated in doxycycline resistance in bacteria were identified in silico in P. falciparum.

Indeed, cyclines bind to proteins S4, S7, S9, and S17 of the $30 \mathrm{~S}$ small ribosomal sub-unit and various ribonucleic acids of the $16 \mathrm{~S}$ ribosomal RNA, preventing the binding of aminoacyl-transfer RNA to site A of the ribosome and thus blocking the elongation step of translation in bacteria [15]. Specific mutations in genes coding these targets can confer resistance to tetracyclines in bacteria. However, no point mutation was found in small sub-unit plastid ribosomal homologue plasmodial genes in African isolates (pfrps7, pfrps9, and pfrps17, although S7, S9, and S17) [11]. It has been also shown that resistance to tetracycline was mediated by mutations in the $16 \mathrm{~S}$ rRNA gene, particularly in Helicobacter pylori or in Propionibacterium acnes [16-18]. An analogue of this gene exists in P. falciparum apicoplast, the small sub-unit ribosomal RNA gene, the pfssrRNA gene, (PFC10_API0057) [19-22]. First, the pfssrRNA gene shares 58 and $62 \%$ identities with the 16S rRNA gene of Propionibacterium acnes and Helicobacter pylori, respectively. Secondly, this gene belongs to the apicoplast, an organelle related to the chloroplast of plant cells that contains its own genome-encoding, prokaryote-like, ribosomal RNAs, tRNAs and some proteins [23]. Three studies confirmed the specific action of cyclines on the apicoplast of $P$. falciparum [24-26]. A parasite exposed to $1 \mu \mathrm{M}$ of doxycycline for $20 \mathrm{~h}$ presented during the next cycle $(72 \mathrm{~h}$ ), the inhibition of apicoplastic replication visualized by confocal fluorescence microscopy, electron microscopy and an analysis of the parasite transcriptome [24]. The most recently published study confirms the action of doxycycline on the apicoplast but in two stages, with an immediate toxic effect and a toxic effect measurable after cell division [25]. A proteomic approach confirmed the specific deregulation of proteins involved in apicoplast metabolism after doxycycline treatment [27].

Thus, the aim of this study was to identify specific point mutations in this plasmodial ribosomal gene, according to what is observed in other species, to determine whether this gene could be involved in reduced susceptibility to doxycycline. For this purpose, the apicoplastic pfssrRNA gene from the 89 African and 89 Thai P. falciparum isolates, belonging to phenotypic groups differing in doxycycline $\mathrm{IC}_{50}$ values and already analysed for $p f t e t Q$ and $p f m d t$ genes, was sequenced and analysed $[9,14]$.

\section{Methods}

\section{Plasmodium falciparum isolates}

A total of 89 African P. falciparum isolates, obtained at the French National Reference Centre for Imported Malaria, Hôpital Bichat, Paris, from patients hospitalized with malaria after having returned to France between January 2006 and December 2010, and 89 isolates obtained from the Shoklo Malaria Research Unit (Mae Sot, Thailand) from patients infected with $P$. falciparum from 2001 to 2010, were used. These isolates were previously tested to evaluate their $p f m d t$ and $p f t e t Q$ genes copy numbers $[9,14]$.

\section{Consent}

Informed consent was not required as the sampling procedures and testing are part of the French national recommendations for the care and surveillance of malaria.

Concerning the Thai isolates, written informed consent translated into the patient's own language was obtained from each participant, whose signature was witnessed. The studies were approved by the Ethics Committees of the Faculty of Tropical Medicine, Mahidol University and Oxford University.

\section{Amplification and sequencing of pfssrRNA gene}

PfssrRNA (PFC10_API0057) was amplified by polymerase chain reaction (PCR) using the following primers: $5^{\prime}$-AGCTAATGGTGAGATTTGAACTCA-3' (forward) and $5^{\prime}$-CGTCGTGAGACAGTTCGGTC-3' (reverse) 
(Eurogentec, Angers, France), designed with the NCBI/ Primer-BLAST online tool.

The reaction mixture included $2 \mu \mathrm{l}$ of genomic DNA, $2.5 \mu \mathrm{l}$ of $10 \times$ reaction buffer (Eurogentec), $0.5 \mu \mathrm{M}$ of each primer, $200 \mu \mathrm{M}$ of deoxynucleoside triphosphate mixture (dGTP, dATP, dTTP and dCTP) (Euromedex, Souffelweyersheim, France), and $1.5 \mathrm{mM}$ of $\mathrm{MgCl}_{2}$ and 1.25 units of RedGoldStar ${ }^{\circledR}$ DNA polymerase (Eurogentec) in a final volume of $25 \mu \mathrm{L}$. The thermal cycler (T3 Biometra, Archamps, France) was programmed as follows: an initial $94{ }^{\circ} \mathrm{C}$ for $2 \mathrm{~min}$ followed by 40 cycles of $94{ }^{\circ} \mathrm{C}$ for $30 \mathrm{~s}, 55^{\circ} \mathrm{C}$ for $30 \mathrm{~s}$ and $60{ }^{\circ} \mathrm{C}$ for $2 \mathrm{~min}$, and a final extension step of $60^{\circ} \mathrm{C}$ for $5 \mathrm{~min}$. The PCR products were loaded on $1 \%$ agarose gel containing $0.5 \mu \mathrm{g} / \mathrm{mL}$ ethidium bromide. Amplicons were purified using the QIAquick 96 PCR BioRobot Kit and an automated protocol on the BioRobot 8000 workstation (Qiagen, Courtaboeuf, France). The purified fragments were sequenced using BigDye Terminator v3.1 Cycle Sequencing Kit (Applied Biosystems) using the following primers: 5'-ACTAGTG TATTTCGGTTAACAGCCG-3' (forward), 5'-ACCCT TATCAAGAGTATGTTTTAACCAT-3' (reverse) and Pf_SSU_rRNA_R1481 CTTAAGAACTTATTCACCG CTA (reverse). The sequence reaction products were purified using the BigDye XTerminator ${ }^{\circledR}$ Purification Kit (Applied Biosystems), in accordance with the manufacturer's instructions. The purified products were sequenced using an ABI Prism 3100 analyser (Applied Biosystems), and the sequences were analysed using Vector NTI advance (TM) software (version 11, Invitrogen, Cergy Pontoise, France).

\section{Results}

In Helicobacter pylori, tetracycline resistance has not been associated with efflux or ribosomal protection proteins but rather attributed to mutations in the 16S rRNAencoding genes that affect the binding site of tetracycline [16-18]. Tetracycline resistance mediated by mutations in the 16S rRNA was first found in Propionibacterium acnes, and a mutation from $\mathrm{G}$ to $\mathrm{C}$ was reported at position 1058 (Escherichia coli numbering) in their 16S rRNA genes [17]. A triplet mutation in the same 16S rRNA domain (965-967; E. coli numbering) was also found [24, $28-30]$ and is located in the primary tetracycline-binding site $[1,15]$. However, the sequencing of $p f s s r R N A$ did not reveal a polymorphism in $P$. falciparum. There was no single nucleotide polymorphism in the pfssrRNA gene in either the 89 African isolates, regardless of the phenotypic group for doxycycline (group A of low doxycycline $\mathrm{IC}_{50}$ [mean $\mathrm{IC}_{50}=3.88 \mu \mathrm{M}$; confident interval $95 \%$ (CI $95 \%$ [ [3.39-4.37], no $=30$ ], group $\mathrm{B}$ of moderate $\mathrm{IC}_{50}$ [mean $\mathrm{IC}_{50}=16.97 \mu \mathrm{M}$; CI $95 \%$ [16.45-17.49]; no = 30]) and group $\mathrm{C}$ of high $\mathrm{IC}_{50}$ [mean $\mathrm{IC}_{50}=34.60 \mu \mathrm{M}, \mathrm{CI}$
$95 \%$ [31.3-37.9], no $=29$ ), or the 89 Thai isolates (group $\mathrm{A}$ [mean $\mathrm{IC}_{50}=3.64 \mu \mathrm{M}, \mathrm{CI} 95 \%$ [3.29-3.99], no $=30$ ], group B [mean $\mathrm{IC}_{50}=14.73 \mu \mathrm{M}$, CI $95 \%$ [14.6-14.85], no $=30$ ] and group C [mean IC50 $=28.94 \mu \mathrm{M}$, CI $95 \%$ [26.51-31.37], no $=29]$ ). No sequence polymorphism in the $p f s s r R N A$ gene was observed by comparison with the reference strain 3D7. This gene was not associated with reduced susceptibility to doxycycline in either African or Thai $P$. falciparum isolates and the small sub-unit ribosomal RNA seemed to be not a target for doxycycline.

\section{Conclusions}

The decreased susceptibility of $P$. falciparum to doxycycline is certainly multigenic. Pfmdt and pftetQ genes polymorphism and number of copies are involved partly to the decreased susceptibility. Intensive research into identifying in vitro markers associated with decreased susceptibility should allow survey of the emergence of doxycycline resistance. Another hypothesis to be explored is some apicoplastic genes, which could be involved in artemisinin resistance [31], such as arps10, encoding the apicoplast ribosomal protein S10 precursor, and $f d$, encoding the ferredoxin protein, a key component of the apicoplast electron transport chain.

\section{Authors' contributions}

$\mathrm{SB}, \mathrm{FN}, J \mathrm{~L}$, and BP conceived and designed the experiments. KS and CW performed the evaluation of doxycycline $I_{50}$ in Mae Sot City, Thailand, using the isotopic method. $\mathrm{SH}$ and $\mathrm{VH}$ performed the evaluation of doxycycline $\mathrm{IC}_{50}$ in Paris, France, using the isotopic method. TG and NW performed the PCR, sequencing and sequence analyses of the pfssrRNA gene. TG, FN, SB and BP wrote the paper. All authors read and approved the final manuscript.

\section{Author details \\ ${ }^{1}$ Unité de Parasitologie, Département d'Infectiologie de Terrain, Institut de Recherche Biomédicale des Armées, Marseille, France. ${ }^{2}$ Unité de Recherche sur les Maladies Infectieuses et Tropicales Emergentes, Aix Marseille Université, UM 63, CNRS 7278, IRD 198, Inserm 1095, Marseille, France. ${ }^{3}$ Fédération des Laboratoires, Hôpital d'Instruction des Armées Saint Anne, Toulon, France. ${ }^{4}$ Centre National de Référence du Paludisme, Marseille, France. ${ }^{5}$ Laboratoire de Parasitologie-Mycologie, Centre National de Référence du Paludisme, APHP, Hôpital Bichat-Claude Bernard, Paris, France. ${ }^{6}$ IRD UMR216, Mère et enfant face aux infections tropicales, Paris, France. ${ }^{7}$ PRES Sorbonne Paris Cité, Faculté des Sciences Pharmaceutiques et Biologiques, Université Paris Descartes, Paris, France. ${ }^{8}$ Shoklo Malaria Research Unit, Mahidol-Oxford Tropi- cal Medicine Research Unit, Faculty of Tropical Medicine, Mahidol University, Mae Sod, Thailand. ${ }^{9}$ Centre for Tropical Medicine, University of Oxford, Oxford, UK. ${ }^{10}$ Direction Inter-Armées du Service de Santé, Cayenne, French Guiana. \\ ${ }^{11}$ Laboratoire de Parasitologie, Institut Pasteur de la Guyane, Cayenne, French Guiana. ${ }^{12}$ Unité de Parasitologie et d'Entomologie, Département des Maladies Infectieuses, Institut de Recherche Biomédicale des Armées, Brétigny sur Orge, France.}

\section{Acknowledgements}

This study was supported by the Délégation Générale pour l'Armement (Grant number 10CO405) and the Institut national de Veille sanitaire (CNR paludisme). The Shoklo Malaria Research Unit is part of the Mahidol Oxford University Research Unit, supported by The Wellcome Trust of Great Britain.

French National Reference Centre for Imported Malaria Study Group Ahmed Aboubacar, Patrice Agnamey, Faïza Ajana, Roger Amira, Nicolas Argy, Sonia Baumard, Pauline Bellanger, Dieudonné Bemba, Jean Beytout, MarieLaure Bigel, Martine Bloch, Richard Bonnet, Alice Borel, Olivier Bouchaud, 
Catherine Branger, Fabrice Bruneel, Monique Cambon, Daniel Camus, Enrique Casalino, Jérome Clain, Sandrine Cojean, Bernadette Cuisenier B, Ludovic De Gentile, Jean-Marie Delarbre, Anne Delaval, Rémy Durand, Emmanuel Dutoit, Odile Eloy, Jean-François Faucher, Albert Faye, Odile Fenneteau, Denis Filisetti, Christian Fulleda, Nadine Godineau, Frédéric Grenouillet, Jean-Pierre Hurst, Houria Ichou, Elizabeth Klein E, Sylvie Lariven, Magalie Lefevre, Monique Lemoine, Olivier Lesens, Caroline Lohmann, Daniel Lusina, Marie-Claude Machouart, Robert Mary, Sophie Matheron, Denis Mechali, Audrey Merrens, Laurence Millon, Sébastien Monnier, Emmanuel Mortier, François Moussel, Olivier Pageot, Nathalie Parez, Pierre Patoz, Alexander Pfaff, Marc Pihet, JeanEtienne Pilo, Isabelle Poilane, Denis Pons, Marie Poupart, Marc Prevel, Lauren Pull, Christophe Rapp, Alexandre Rivier, Emily Ronez, Daniel Rotten, AnneLaure Simonet, Jean-Yves Siriez, Christophe Strady, Audrey Therby, Michel Thibault, Maxime Thouvenin, Dominique Toubas.

\section{Compliance with ethical guidelines}

\section{Competing interests}

The authors have declared that they have no competing interests.

Received: 5 July 2015 Accepted: 29 August 2015

Published online: 17 September 2015

\section{References}

1. Chopra I, Roberts M. Tetracycline antibiotics: mode of action, applications, molecular biology, and epidemiology of bacterial resistance. Microbiol Mol Biol Rev. 2001;65:232-60.

2. World Health Organization. Guidelines for the treatment of malaria. 2nd ed. Geneva: World Health Organization; 2011.

3. Institut National de Veille Sanitaire. Recommandations sanitaires pour les voyageurs, 2015. BEH. 2015;21-22:361-421.

4. Shanks GD, Edstein MD, Suriyamongkol V, Timsaad S, Webster HK. Malaria chemoprophylaxis using proguanil/dapsone combinations on the ThaiCambodian border. Am J Trop Med Hyg. 1992;46:643-8.

5. Pang L, Limsomwong N, Singharaj P. Prophylactic treatment of vivax and falciparum malaria with low-dose doxycycline. J Infect Dis. 1988;158:1124-7.

6. Wallace MR, Sharp TW, Smoak B, Iriye C, Rozmajzl P, Thornton SA, et al. Malaria among United States troops in Somalia. Am J Med. 1996;100:49-55.

7. Jacobs RL, Koontz LC. Plasmodium berghei: development of resistance to clindamycin and minocycline in mice. Exp Parasitol. 1976;40:116-23.

8. Madamet M, Gaillard T, Velut G, Ficko C, Houzé P, Bylicki C, et al. Malaria prophylactic failure with doxycycline. Emerg Infect Dis. 2015;21:1485-6.

9. Gaillard T, Briolant S, Houzé S, Baragatti M, Wurtz N, Hubert V, et al. PftetQ and pfmdt copy numbers as predictive molecular markers of decreased ex vivo doxycycline susceptibility in imported Plasmodium falciparum malaria. Malar J. 2013;12:414.

10. Briolant S, Baragatti M, Parola P, Simon F, Tall A, Sokhna C, et al. Multinormal in vitro distribution model suitable for the distribution of Plasmodium falciparum chemosusceptibility to doxycycline. Antimicrob Agents Chemother. 2009;53:688-95.

11. Briolant S, Wurtz N, Zettor A, Rogier C, Pradines B. Susceptibility of Plasmodium falciparum isolates to doxycycline is associated with pftetQ sequence polymorphisms and pftetQ and pfmdt copy numbers. J Infect Dis. 2010;201:153-9.

12. Achieng AO, Ingasia LA, Juma DW, Cheruiyot AC, Okudo CA, Yeda RA, et al. Doxycycline reduced in vitro susceptibility in Plasmodium falciparum
Kenyan field isolates is associated with PftetQ KYNNNN sequence polymorphism. Antimicrob Agents Chemother. 2014;58:5894-9.

13. Gaillard T, Fall B, Tall A, Wurtz N, Diatta B, Lavina M, et al. Absence of association between ex vivo susceptibility to doxycycline and pftetQ and pfmdt copy numbers in Plasmodium falciparum isolates from Dakar, Senegal. Clin Microbiol Infect. 2012;18:238-40.

14. Gaillard T, Sriprawat K, Briolant S, Wangsing C, Wurtz N, Baragatti M, et al Molecular markers and in vitro susceptibility to doxycycline in Plasmodium falciparum isolates from Thailand. Antimicrob Agents Chemother. 2015;59:5080-3.

15. Pioletti M, Schlünzen F, Harms J, Zarivach R, Glühmann M, Avila H, et al. Crystal structures of complexes of the small ribosomal subunit with tetracycline, edeine and IF3. EMBO J. 2001;20:1829-39.

16. Gerrits MM, de Zoete MR, Arents NLA, Kuipers EJ, Kusters JG. 16S rRNA mutation-mediated tetracycline resistance in Helicobacter pylori. Antimicrob Agents Chemother. 2002;46:2996-3000.

17. Ross Jl, Eady EA, Cove JH, Cunliffe WJ. $16 \mathrm{~S}$ rRNA mutation associated with tetracycline resistance in a gram-positive bacterium. Antimicrob Agents Chemother. 1998;42:1702-5.

18. Trieber CA, Taylor DE. Mutations in the 165 rRNA genes of Helicobacter pylori mediate resistance to tetracycline. J Bacteriol. 2002;184:2131-40.

19. Feagin JE. The 6-kb element of Plasmodium falciparum encodes mitochondrial cytochrome genes. Mol Biochem Parasitol. 1992;52:145-8.

20. Feagin JE, Werner E, Gardner MJ, Williamson DH, Wilson RJ. Homologies between the contiguous and fragmented rRNAs of the two Plasmodium falciparum extrachromosomal DNAs are limited to core sequences. Nucleic Acids Res. 1992;20:879-87.

21. Goodman CD, Su V, McFadden GI. The effects of anti-bacterials on the malaria parasite Plasmodium falciparum. Mol Biochem Parasitol. 2007;152:181-91.

22. Dahl EL, Rosenthal PJ. Multiple antibiotics exert delayed effects against the Plasmodium falciparum apicoplast. Antimicrob Agents Chemother. 2007:51:3485-90.

23. Dahl EL, Shock JL, Shenai BR, Gut J, DeRisi JL, Rosenthal PJ. Tetracyclines specifically target the apicoplast of the malaria parasite Plasmodium falciparum. Antimicrob Agents Chemother. 2006;50:3124-31.

24. Fichera ME, Roos DS. A plastid organelle as a drug target in apicomplexan parasites. Nature. 1997;390:407-9.

25. Yeh E, DeRisi JL. Chemical rescue of malaria parasites lacking an apicoplast defines organelle function in blood-stage Plasmodium falciparum. PLOS Biol. 2011;9:1001138.

26. Clyde DF, Miller RM, DuPont HL, Hornick RB. Antimalarial effects of tetracyclines in man. J Trop Med Hyg. 1971;74:238-42.

27. Briolant S, Almeras L, Belghazi M, Boucomont-Chapeaublanc E, Wurtz N, Fontaine A, et al. Plasmodium falciparum proteome changes in response to doxycycline treatment. Malar J. 2010;9:141.

28. Trieber CA, Burkhardt N, Nierhaus KH, Taylor DE. Ribosomal protection from tetracycline mediated by $\operatorname{Tet}(\mathrm{O})$ : Tet $(\mathrm{O})$ interaction with ribosomes is GTP-dependent. Biol Chem. 1998;379:847-55.

29. Dailidiene D, Bertoli MT, Miciuleviciene J, Mukhopadhyay AK, Dailide G, Pascasio MA, et al. Emergence of tetracycline resistance in Helicobacter pylori: multiple mutational changes in 16S ribosomal DNA and other genetic loci. Antimicrob Agents Chemother. 2002;46:3940-6.

30. Ribeiro ML, Gerrits MM, Benvengo YHB, Berning M, Godoy APO, Kuipers EJ, et al. Detection of high-level tetracycline resistance in clinical isolates of Helicobacter pylori using PCR-RFLP. FEMS Immunol Med Microbiol. 2004;40:57-61.

31. Miotto O, Amato R, Ashley EA, Maclnnis B, Almagro-Garcia J, Amaratunga $C$, et al. Genetic architecture of artemisinin-resistant Plasmodium falciparum. Nat Genet. 2015;47:226-34 